\title{
Flexural Behavior of Extruded DFRCC Panel and Reinforced Concrete Composite Slab
}

\author{
Chang-Geun Cho, ${ }^{1}$ Bang Yeon Lee, ${ }^{2}$ Yun Yong Kim, ${ }^{3}$ Byung-Chan Han, ${ }^{4}$ and Seung-Jung Lee ${ }^{1}$ \\ ${ }^{1}$ School of Architecture, Chosun University, Seosuk-Dong 375, Dong-Gu, Gwangju 501-759, Republic of Korea \\ ${ }^{2}$ School of Architecture, Chonnam National University, Gwangju 500-757, Republic of Korea \\ ${ }^{3}$ Department of Civil Engineering, Chungnam National University, Daejeon 305-764, Republic of Korea \\ ${ }^{4}$ Department of Remolding Architecture, Woosong Information College, Daejeon 300-715, Republic of Korea \\ Correspondence should be addressed to Yun Yong Kim, yunkim@cnu.ac.kr
}

Received 15 December 2011; Accepted 18 February 2012

Academic Editor: Nai-Qian Feng

Copyright (๑) 2012 Chang-Geun Cho et al. This is an open access article distributed under the Creative Commons Attribution License, which permits unrestricted use, distribution, and reproduction in any medium, provided the original work is properly cited.

\begin{abstract}
This paper presents a new reinforced concrete (RC) composite slab system by applying an extruded Ductile Fiber Reinforced Cement Composite (DFRCC) panel. In the proposed composite slab system, the DFRCC panel, which has ribs to allow for complete composite action, is manufactured by extrusion process; then, the longitudinal and transverse reinforcements, both at the bottom and the top, are placed, and finally the topping concrete is placed. In order to investigate the flexural behavior of the proposed composite slab system, a series of bending tests was performed. From the test results, it was found that the extruded DFRCC panel has good deformation-hardening behavior under flexural loading conditions and that the developed composite slab system, applied with an extruded DFRCC panel, exhibits higher flexural performance compared to conventional RC slab system in terms of the stiffness, load-bearing capacity, ductility, and cracking control.
\end{abstract}

\section{Introduction}

In multistory building structures the slab and floor units account for something like 50 to $60 \%$ of the material requirements. The thickness of the slabs is selected so that deflections and cracks will not be a problem. However, for very heavily loaded slabs, such as slabs supporting large-span lengths and slabs of the garage, it is unavoidable that the selfweight of the slabs will be increased because the thickness of those slabs must be increased.

On the other hand, a number of studies have been reported in which the use of high-ductile and high-performance fiber-reinforced cementitious composites such as Ductile Fiber-Reinforced Cement Composite (DFRCC) has been shown to significantly enhance the brittleness of concrete after cracking. DFRCC retains a high-ductile deformation capacity through the bridging of microcracks by synthetic fibers, where bridging in turn leads to multiple cracking [1-3]. The fundamental requirement for matrix multiple cracking, which was first characterized in a previous study
[4-6], is that steady-state flat crack propagation must prevail under tension. The production methods of DFRCC include cast in place, spray, and extrusion [7, 8]. Among these methods, extrusion is a process used to create a precast product of a fixed cross-section. By adopting the extrusion process for DFRCC, the mechanical properties such as strength, elastic modulus, and ductility can be enhanced due to the lower porosity of the extruded composites, which is attributed to mechanical compaction as well as to the aligned orientation of fibers. Fundamental research has been preformed to evaluate the mechanical properties of extruded DFRCC [9-13]. However, there have been only few studies on the structural application of an extruded DFRCC panel such as composite slab.

Therefore, the purpose of the current study is to develop a new approach for DFRCC and reinforced concrete (RC) composite slab systems by applying an extruded DFRCC panel; this new approach has some advantages in terms of minimization of crack width, pseudo-deformation hardening behavior based on multiple cracking, high-ductile 
TABle 1: Properties of cement and silica powder.

\begin{tabular}{lccccccccc}
\hline Types & Density $\left(\mathrm{g} / \mathrm{mm}^{3}\right)$ & Fineness $\left(\mathrm{m}^{2} / \mathrm{kg}\right)$ & $\mathrm{SiO}_{2}$ & $\mathrm{Al}_{2} \mathrm{O}_{3}$ & $\mathrm{Fe}_{2} \mathrm{O}_{3}$ & $\mathrm{CaO}$ & $\mathrm{MgO}^{2}$ & $\mathrm{SO}_{3}$ & $\mathrm{LOI}^{*}$ \\
\hline Cement & 3.15 & 363 & 22.73 & 5.93 & 3.37 & 61.73 & 2.53 & 1.97 & 1.74 \\
Silica Power & 2.66 & 379 & 95.5 & 1.95 & 0.76 & - & - & - & 1.79 \\
\hline
\end{tabular}

* Loss on ignition.

TABle 2: Properties of fibers.

\begin{tabular}{lcccccccccc}
\hline Ingredient & $\begin{array}{c}\text { Density } \\
\left(\mathrm{g} / \mathrm{mm}^{3}\right)\end{array}$ & $\begin{array}{c}\text { Length } \\
(\mathrm{mm})\end{array}$ & $\begin{array}{c}\text { Diameter } \\
(\mu \mathrm{m})\end{array}$ & $\begin{array}{c}\text { Surface } \\
\text { treatment }\end{array}$ & $\begin{array}{c}\text { Melting } \\
\text { point }\left({ }^{\circ} \mathrm{C}\right)\end{array}$ & $\begin{array}{c}\text { Thermal } \\
\text { decom- position } \\
\left({ }^{\circ} \mathrm{C}\right)\end{array}$ & $\begin{array}{c}\text { Tensile } \\
\text { strength } \\
(\mathrm{MPa})\end{array}$ & $\begin{array}{c}\text { Young's } \\
\text { modulus } \\
(\mathrm{GPa})\end{array}$ & $\begin{array}{c}\text { Elongation } \\
(\%)\end{array}$ & $\begin{array}{c}\text { Alkali } \\
\text { resistance }\end{array}$ \\
\hline PVA & 1.3 & 8 & 39 & $\begin{array}{c}\text { Oiling } \\
\text { agent }\end{array}$ & 170 & 263 & 1,700 & 29.4 & $3 \sim 113$ & High \\
\hline
\end{tabular}

TABLE 3: Mixture proportion of extrusion DFRCC panel.

\begin{tabular}{lccccccc}
\hline Name & Cement & Water & DFRCC powder* & Silica powder & SP & HPMC $^{\dagger}$ & PVA (vol.\%) $^{*}$ \\
\hline DFRCC & 1.0 & 0.30 & 0.88 & 1.1 & 0.0061 & 0.018 & 2.0 \\
\hline
\end{tabular}

All numbers are mass ratios of cement weight.

* DFRCC powder: BFS, Sepiolite, $\mathrm{Mg}(\mathrm{OH})_{2}, \mathrm{CaCO}_{3}, \mathrm{CSA}, \mathrm{Al}(\mathrm{OH})_{3}, \mathrm{CW} 150$.

${ }^{\dagger}$ Hydroxypropylmethyl cellulose.

flexural behavior, and easy to realize formless or half-precast construction of the slab system. The DFRCC panel was extruded with the thickness of about $20 \mathrm{~mm}$ and had ribs in order to complete the composite action with topping concrete. The composite slab system was composed in such a way that the DFRCC extruded panel was located at the bottom of the slab; reinforcements were assembled and located on the panel; finally, the topping concrete was placed in the field. The developed slab system was evaluated from experimental and analytical viewpoints.

\section{Manufacturing of Extruded DFRCC Panel}

2.1. Materials and Mixture Composition. Ordinary Portland Cement (OPC) with a density of $3.15 \mathrm{~g} / \mathrm{cm}^{3}$ and a specific surface of $363 \mathrm{~m}^{2} / \mathrm{kg}$ was used as the main binder; silica powder with a density of $2.66 \mathrm{~g} / \mathrm{cm}^{3}$ and a specific surface of $379 \mathrm{~m}^{2} / \mathrm{kg}$ was used as an additive. The specific properties of the OPC and the silica powder used in this study are presented in Table 1. DFRCC powder, which is a composition of pulverulent materials, was also used as an additive to improve the strength of the matrix and to increase fire resistance. A polyvinylalcohol (PVA) fiber (Kuraray Co. Ltd., REC15) with a diameter of $39 \mu \mathrm{m}$ and a length of $8 \mathrm{~mm}$ was used as the reinforcing fiber. Table 2 presents the physical and chemical characteristics of the fibers.

The required fresh properties for the extruding of cementitious composite are quite different from those of normal cementitious composite because the shape of the composite must be maintained immediately after extrusion. Therefore, a preliminary experiment was carried out to determine the mixture composition. From the preliminary experiment, it was found that a water to binder ratio of $10 \%$ is proper for keeping the shape of the matrix after extrusion. PVA fiber over 2 vol. \% is generally used to make a fiber-reinforced concrete that exhibits deformation-hardening behavior based on multiple cracking [14]. However, it was found that it is hard to mix the composite with 0.5 vol.\% PVA fiber. Therefore, superplasticizer (SP) and hydroxypropylmethyl cellulose (HPMC, Atex Co., Korea) were used and the amount of these additives was optimized to prevent the clumping of fibers and to homogeneously disperse the fiber without increasing the water-to-binder ratio. The mixture composition for the extruded DFRCC panel is presented in Table 3 .

2.2. Manufacturing Process and Curing Condition. The dry mixing of solid materials including cement, silica powder, pulverulent material, and fiber was performed using an Omni mixer for 4 minutes; wet-mixing was then performed using a kneader mixer for a period of 6 minutes. Finally, extrusion was performed for 5 minutes. Therefore, the total processing time was 15 minutes. Photographs of the extrusion equipment and the extruding process are given in Figures 1 and 2, respectively.

For the dimensional stability and the fast achievement of the required mechanical properties, autoclave curing is generally adopted for extruded products. In this study, an alternative curing method was developed to prevent damage to the PVA fibers because the melting point of PVA fiber is $170^{\circ} \mathrm{C}$. The curing method proposed in this study is composed of precuring for 5 hours after extrusion and curing 
TABLE 4: Experimental results for DFRCC panel specimens.

\begin{tabular}{lccccccc}
\hline Name & $f_{i}(\mathrm{MPa})$ & $\delta_{i}(\mathrm{~mm})$ & $f(\mathrm{MPa})$ & $\delta(\mathrm{mm})$ & $\delta / \delta_{i}$ & Stiffness $(\mathrm{kN} / \mathrm{mm})$ & No. of cracks \\
\hline DFRCC & 29.1 & 0.675 & 37.0 & 6.11 & 9.01 & 42.1 & 12 \\
\hline
\end{tabular}

$f_{i}$ : flexural strength at initial crack, $\delta_{i}$ : midspan deflection at $f_{i}, f$ : maximum flexural strength, $\delta$ : midspan deflection at $f$.

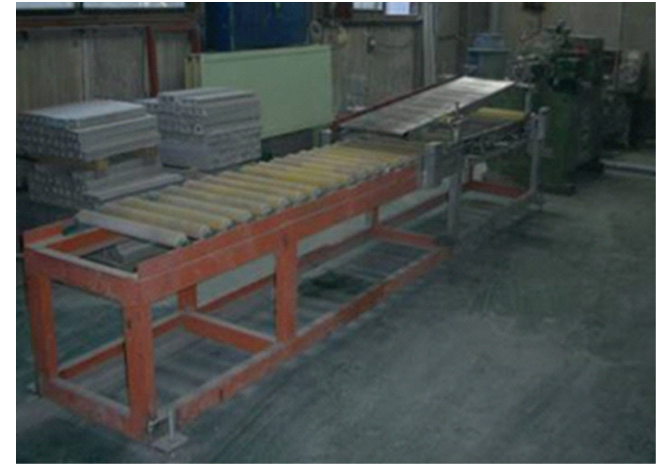

FIgURE 1: Extrusion equipment.

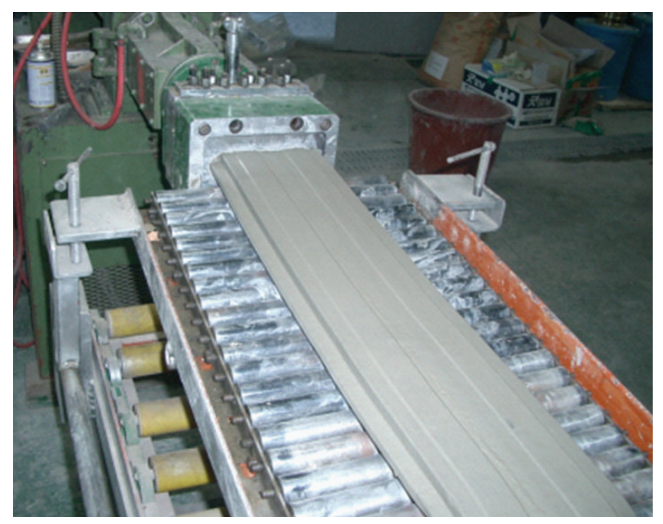

FIGURE 2: Extruding process of DFRCC panel.

at $50^{\circ} \mathrm{C}$ during a period of 3 days. A test to check for deformation or deterioration of the extruded DFRCC panel was performed at 3 days. No deterioration or deformation of the panel was observed.

\section{Bending Test of Extruded DFRCC Panels}

3.1. Specimens of Extruded DFRCC Panels. The flexural performance of the extruded DFRCC panel was evaluated by a four-point bending test. Figure 3 shows the dimensions of the panel specimen and the test setup. Tests were conducted using a UTM (Universal Testing Machine) under displacement control. Two LVDTs (Linear Variable Displacement Transducers) were installed at midspan of the specimen to measure the deflection. The flexural stress was calculated by the following equation

$$
f_{b}=\frac{P \times l}{b \times d^{2}}
$$

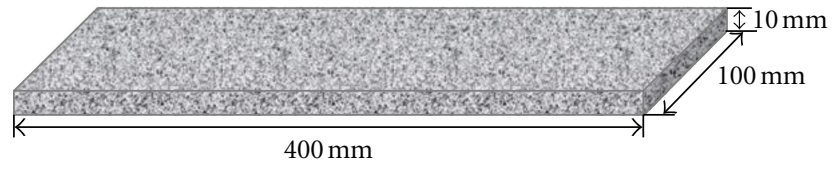

(a) Dimensions of panel specimen

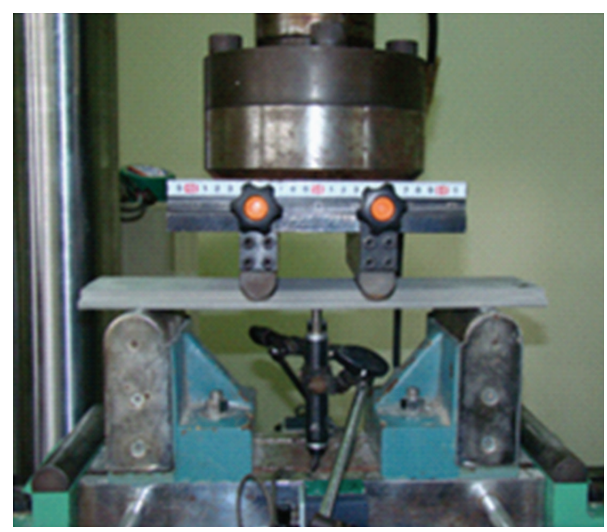

(b) Test setup

Figure 3: Bending test of extruded DFRCC panel.

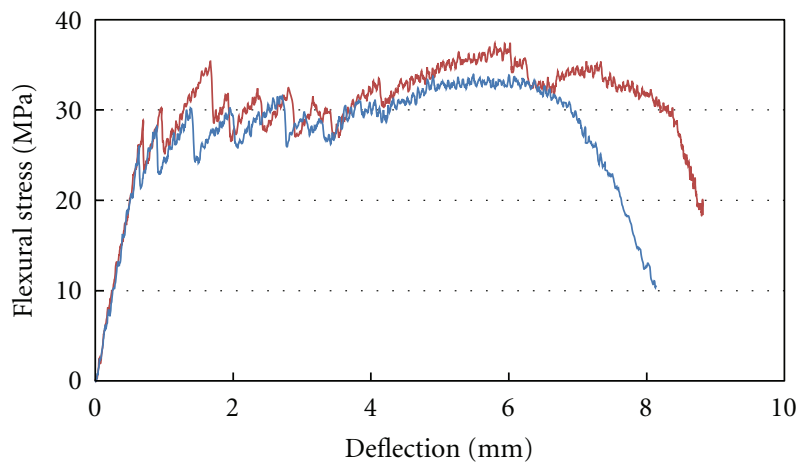

FIGURE 4: Flexural stress-deflection curves of extruded DFRCC panels.

where $f$ is the flexural strength $(\mathrm{MPa}), P$ is the maximum load $(N), l$ is the span length, and $b$ and $d$ are the width and height of the specimen, respectively.

3.2. Results of Panel Bending Test. The bending test results for the extruded DFRCC panels are presented in Table 4 and in Figure 4. The two specimens exhibited high-ductile and deformation-hardening behaviors after fiber cracking. The average flexural strength of the two specimens was $37.0 \mathrm{MPa}$ and the ratio of deflection corresponding to the flexural strength and deflection at first cracking was 9.01. The average 


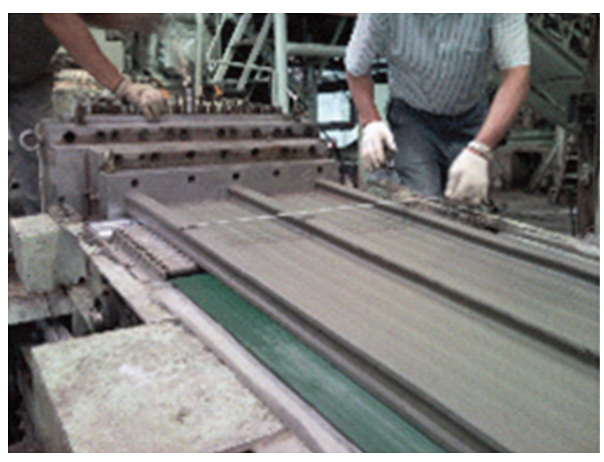

(a)

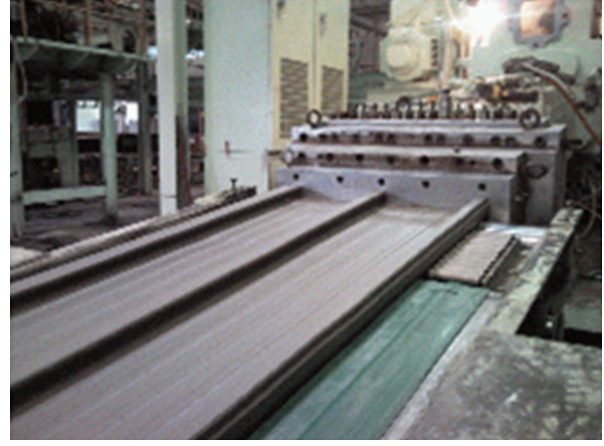

(b)

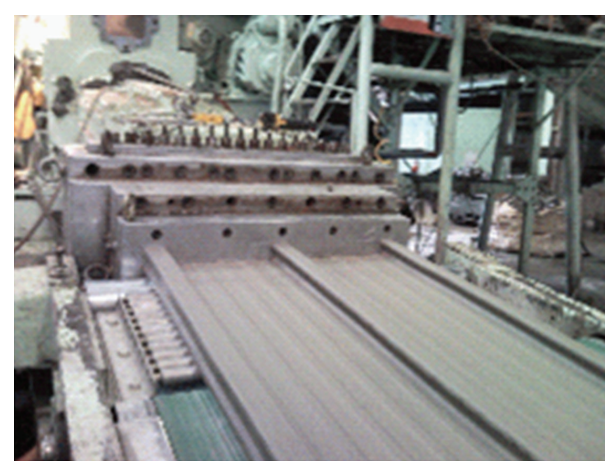

(c)

FIGURE 5: Extrusion of DFRCC panel for slab system.

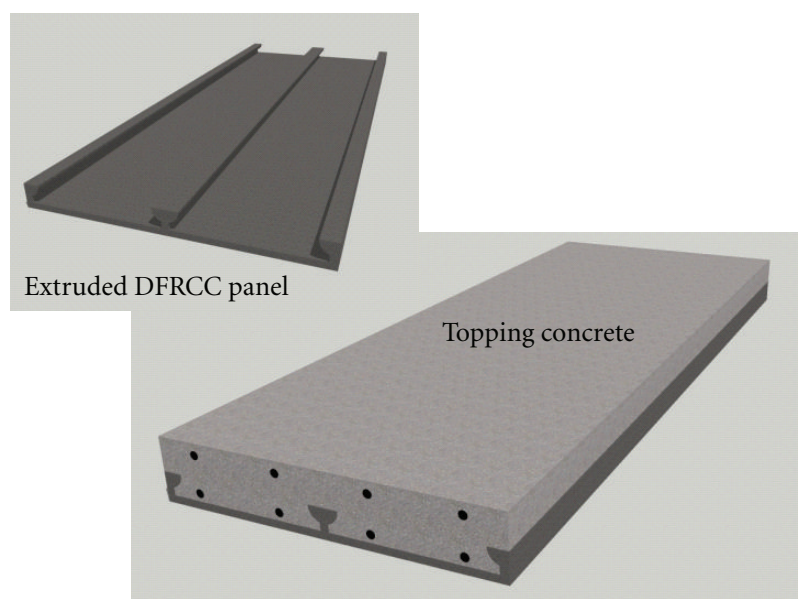

FIGURE 6: Cross-section of RC composite slab system with extruded DFRCC panel.

stiffness and number of cracks of the extruded DFRCC panel were $42.1 \mathrm{kN} / \mathrm{mm}$ and 12 , respectively.

\section{Composite Slab System Designed with Extruded DFRCC Panel}

By applying the extruded DFRCC panel, a new RC composite slab system is proposed. In order to apply the extruded
DFRCC panel in the newly developed slab system, the DFRCC panel was manufactured by extrusion process, as shown in Figure 5. The extruded DFRCC panel has three ribs, allowing it to obtain completely composite action with topping concrete, as shown in Figure 6, which gives a crosssection of the developed RC composite slab system applied with the extruded DFRCC panel. For the field construction of the developed slab system, the extruded DFRCC panel can be manufactured in a factory as a precast product and the slab system can be manufactured in the construction field as a schematic construction process as shown in Figure 7.

\section{Flexural Experiments of Developed Slab System}

In order to investigate the flexural performance of the developed RC composite slab system with applied extruded DFRCC panel, a series of four-point slab bending tests was conducted to compare the new system's performance with that of the conventional RC slab system.

5.1. Specimens of Composite Slab Systems. In order to evaluate the proposed $\mathrm{RC}$ composite slab system with the extruded DFRCC panel, a series of specimens of one-way slabs was manufactured. As shown in Figure 8, each specimen had a span length of $3,400 \mathrm{~mm}$ and a cross-section of $600 \mathrm{~mm} \times$ $180 \mathrm{~mm}$. The experimental variable for each slab specimen is presented in Table 5. Specimen RC-0 is a conventional 


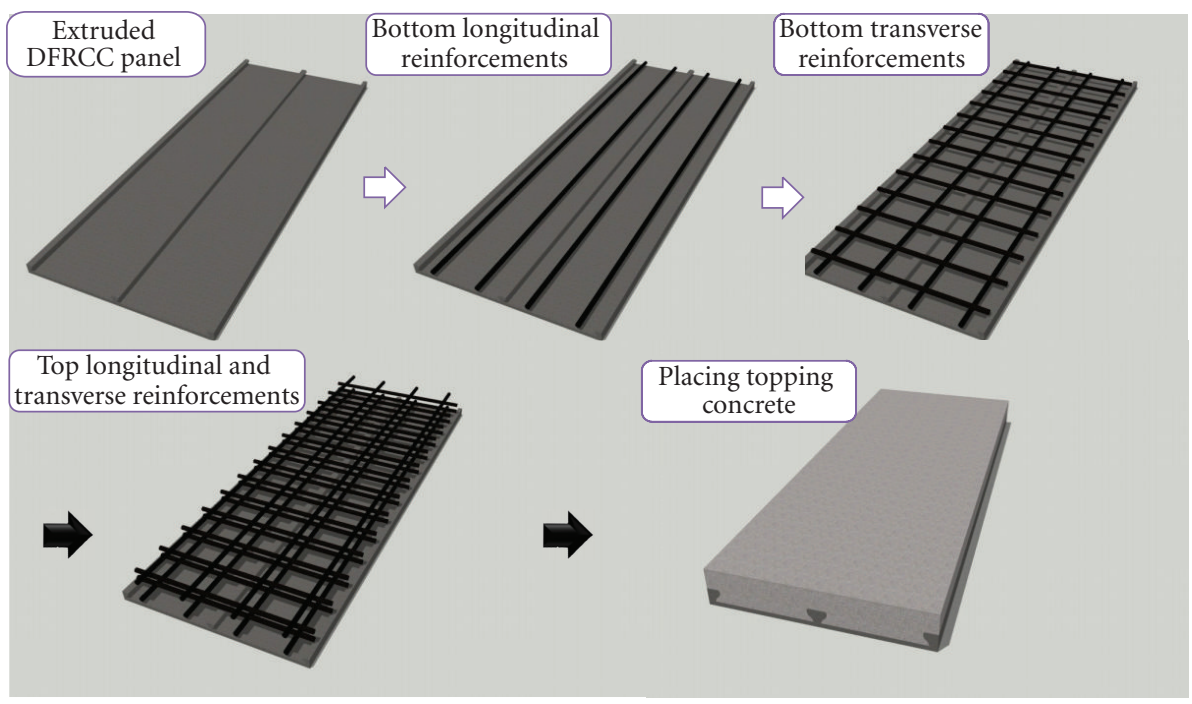

FIGURE 7: Schematic construction process of slab system.

Transverse bars: D13 at $400 \mathrm{~mm}$ for all specimens Longitudinal bars: D10 at $150 \mathrm{~mm}$ for DFRCC-R

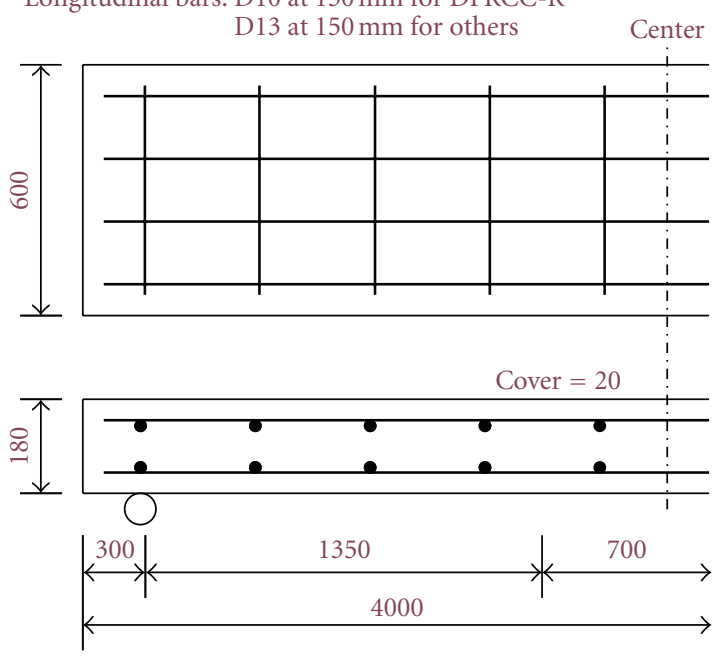

Figure 8: Reinforcement details of slab specimens.

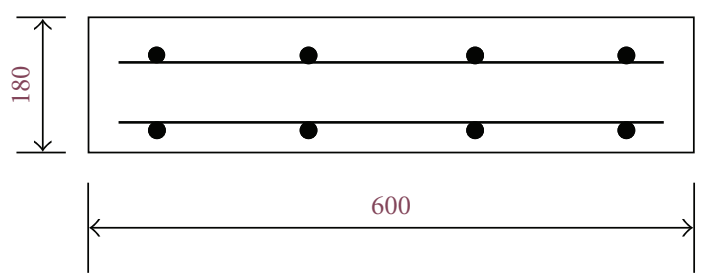

(a) RC-0

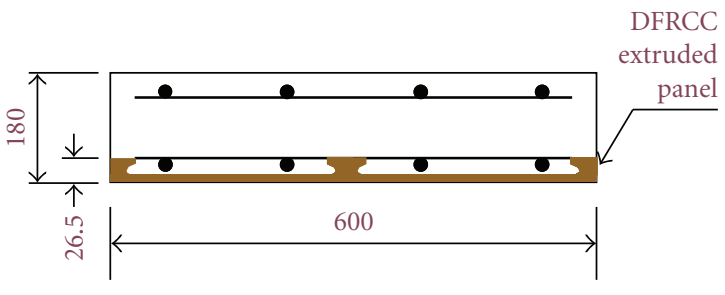

(b) DFRCC-P and DFRCC-R

FIGURE 9: Cross-section of slab specimens.
RC slab specimen. Specimens DFRCC-P and DFRCC-R are designed as a composite slab system with an extruded DFRCC panel, as shown in Figure 9. Specimen DFRCC$\mathrm{R}$ is designed to have longitudinal reinforcements of D10 at $150 \mathrm{~mm}$, but all other specimens are designed to have longitudinal reinforcements of D13 at $150 \mathrm{~mm}$, which leads to a different reinforcement ratio. In order to manufacture the three specimens of the composite slab system, as shown in Figure 10, the DFRCC extrusion panel was first located at the bottom of a slab with a thickness of $20 \mathrm{~mm}$; next, the longitudinal and transverse reinforcements, both at the bottom and the top, were placed; finally the topping concrete was placed. In order to obtain completely composite action between the DFRCC panel and the concrete, the DFRCC panel was extruded with three ribs.
5.2. Bending Test of Slab Systems. The three specimens of the slab systems were tested by four-point bending test under simply-supported conditions, as shown in Figure 11. The bending test was conducted using a UTM (Universal Testing Machine). The pure bending span length between two loading points was $700 \mathrm{~mm}$. Monotonic transverse load was applied in order to lead to the failure of each specimen by crushing of concrete in compression. The deflection at midspan of each specimen was measured using LVDT installed in the vertical direction at midspan. For the calculation of curvature, additional LVDTs were installed in the horizontal direction at the bottom and top of specimens.

5.3. Test Results of Slab Systems. Figure 12 shows the crack patterns at midspan for the three slab specimens. For 
TABLE 5: Experimental variables of slab specimens.

\begin{tabular}{|c|c|c|c|c|c|c|c|}
\hline Specimen & $\begin{array}{l}\text { Section } \\
(\mathrm{mm})\end{array}$ & $\begin{array}{c}\text { DFRCC } \\
\text { panel }(\mathrm{mm})\end{array}$ & $\begin{array}{c}\text { Longitudinal } \\
\text { reinforcement }\end{array}$ & $\rho_{s}(\%)$ & $\begin{array}{c}\text { Transverse } \\
\text { reinforcement }\end{array}$ & $f_{c}^{\prime}(\mathrm{MPa})$ & $f_{y}(\mathrm{MPa})$ \\
\hline RC-0 & \multirow{3}{*}{$600 \times 180$} & - & D13 at $150 \mathrm{~mm}$ & 0.47 & $\mathrm{D} 10$ at $150 \mathrm{~mm}$ & \multirow{3}{*}{24} & \multirow{3}{*}{412} \\
\hline DFRCC-P & & $600 \times 20$ & $\mathrm{D} 13$ at $150 \mathrm{~mm}$ & 0.47 & $\mathrm{D} 10$ at $150 \mathrm{~mm}$ & & \\
\hline DFRCC-R & & $600 \times 20$ & $\mathrm{D} 10$ at $150 \mathrm{~mm}$ & 0.26 & $\mathrm{D} 10$ at $150 \mathrm{~mm}$ & & \\
\hline
\end{tabular}

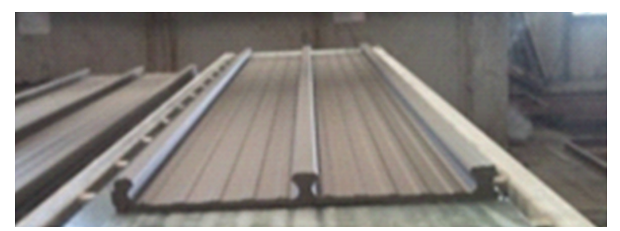

(a) Extruded DFRCC panel

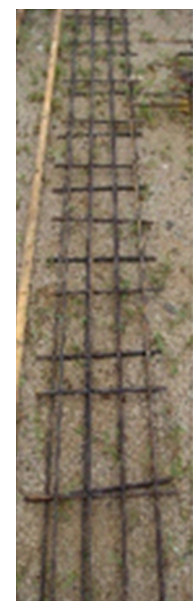

(b) Rebar cage

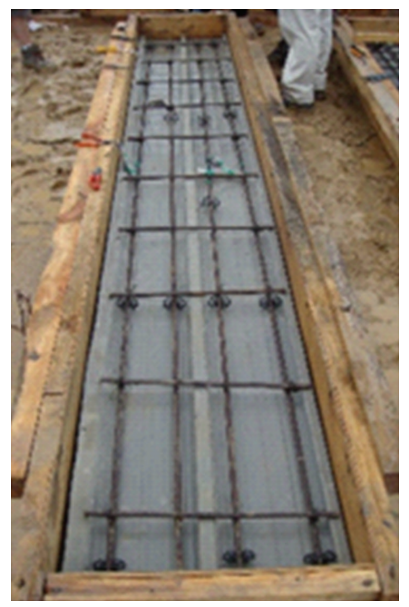

(c) Panel and rebar installation

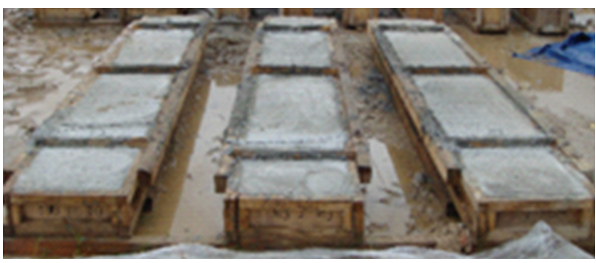

(d) Topping concrete placing in field

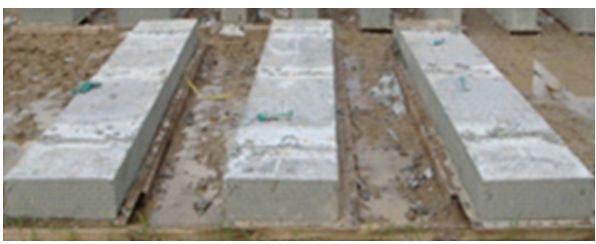

(e) Specimens after wet-curing

Figure 10: Manufacturing process of slab specimen.

Specimen RC-0, the initial crack took place near the midspan of the concrete at a load of $7.03 \mathrm{kN}$; the cracks spread from the midspan to the support with a crack spacing of $100 \mathrm{~mm} \sim 150 \mathrm{~mm}$. After the load level of yielding, the width of cracks greatly increased until failure of the specimen was

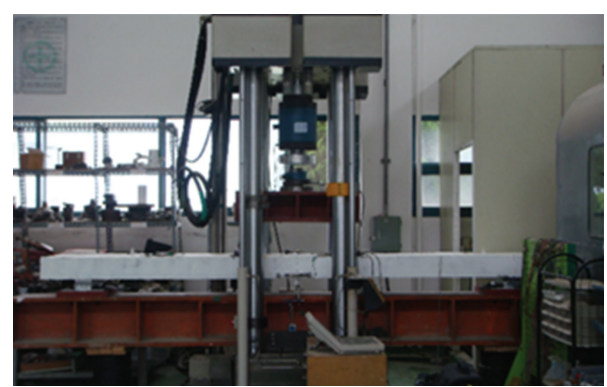

FIGURE 11: Four-point bending test.

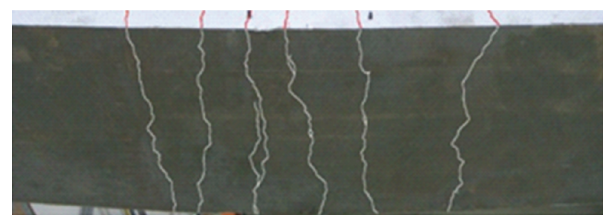

(a) RC-0 specimen

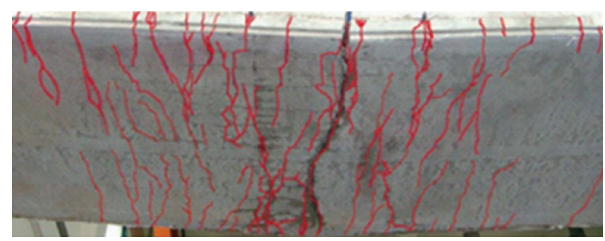

(b) DFRCC-P specimen

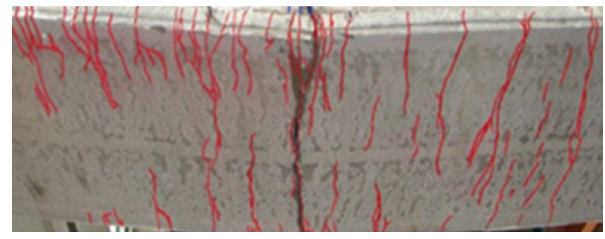

(c) DFRCC-R specimen

FIGURE 12: Crack pattern marked with ink pen at midspan zone.

reached. The final failure of the specimen was obtained by the crushing of the concrete at the top of the specimen. For Specimen DFRCC-P, an initial crack was observed near the midspan on the DFRCC panel at a load of $13.1 \mathrm{kN}$. After reaching the yield load, the crack width did not increase. After reaching the midspan deflection of $30 \mathrm{~mm}$, multiple microcracks on the DFRCC panel were found to spread near the midspan and the specimen resisted stably with highductile bending behavior to reach a midspan deflection of 
$103 \mathrm{~mm}$. The final failure was obtained by the crushing of the concrete at the top of specimen, just as was done with Specimen RC-0. Any delamination (or debonding) between two materials was not observed during the bending test. This is attributed to the three ribs of extruded DFRCC panel. The ribs allow the panel to achieve sufficient composite action with topping concrete. In addition, this composite slab exhibits thin one-way slab behavior with a/d (shear span to depth ratio) of approximately 8.4. The cracking pattern and failure of Specimen DFRCC-R were very similar to those of Specimen DFRCC-P. Specimen DFRCC-R showed multiple micro-cracks on the DFRCC panel. Any delamination (or debonding) between two materials in Specimen DFRCC-R was also not observed during the bending test. From this observation, it is verified that the crack width of a slab can be controlled by applying an extruded DFRCC panel.

Figure 13 shows the measured load-deflection curves of the three slab specimens. The maximum loads of Specimens DFRCC-P and DFRCC-R were $62.3 \mathrm{kN}$ and $52.5 \mathrm{kN}$, which are 1.21 and 1.02 times that of Specimen RC-0, respectively. Although the load-bearing capacity of DFRCC-R was decreased due to the decreased reinforcement ratio, which is about half that of Specimens RC-0 and DFRCC-P, Specimen DFRCC-R showed a load-bearing capacity similar to that of Specimen RC-0. This is attributed to the high ductility of the DFRCC panel, where ductility is based on multiple cracking and deformation hardening behavior.

Figure 14 shows the measured bending moment-curvature curves of the three slab specimens. The performance of each slab specimen based on the bending moment curvature is similar to that based on load-deflection curves. The yield moment of Specimen DFRCC-P was 1.13 times higher than that of Specimen RC-0. On the other hand, the yield curvature of Specimen DFRCC-P was 0.53 times lower than that of Specimen RC-0. From these test results, Specimen DFRCC-P is found to have stiffness higher than that of Specimen RC-0. This discrepancy is attributed to the tension stiffening effect between the reinforcing steel and the DFRCC after the first cracking. The maximum moment and maximum curvature values for Specimen DFRCC-P were $41.8 \mathrm{kN} \cdot \mathrm{m}$ and $2.18 \times 10^{-5} / \mathrm{mm}$, which were 1.21 times and 1.42 times those values of RC-0, respectively. The curvature ductility ratio of Specimen DFRCC-P, which is the maximum curvature and yield curvature ratio, was 13.4, which is 2.70 times that of Specimen RC-0. From these test results, it was verified that the stiffness and ductility of a slab can be improved by applying an extruded DFRCC panel. The yield moment and yield curvature of Specimen DFRCC-R were $32.1 \mathrm{kN} \cdot \mathrm{m}$ and $2.96 \times 10^{-5} / \mathrm{mm}$, respectively, where values were 1.02 times and 0.96 times those of Specimen RC-0. On the other hand, the maximum moment and maximum curvature of Specimen DFRCC-R were 1.05 times and 1.38 times those values of Specimen RC0 . The curvature ductility ratio of Specimen DFRCC-R was 7.13, which was 1.44 times higher than that of Specimen RC0 . From these test results, it was found that higher ductility as well as sufficient load-bearing capacity in a slab system can be achieved with a lower reinforcement ratio by applying an extruded DFRCC panel. The deflection ductility ratios,

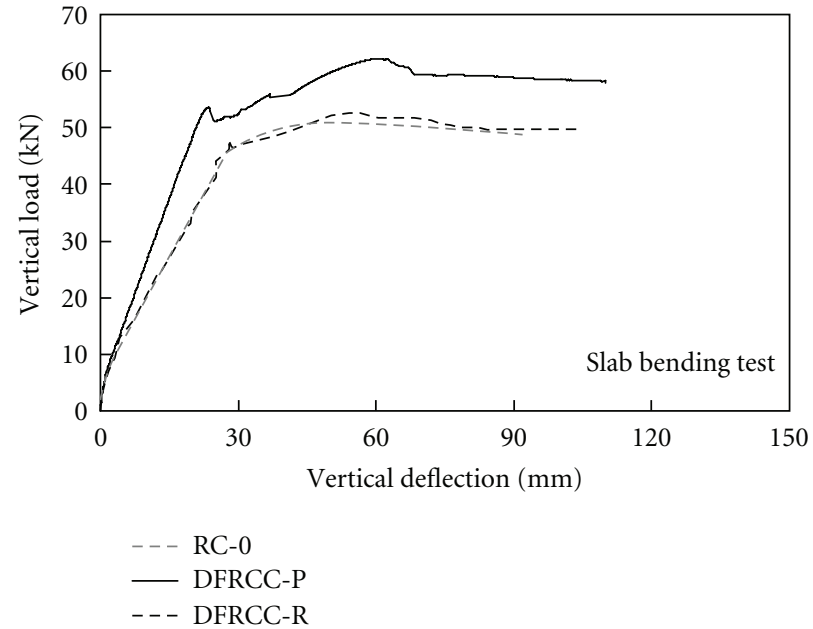

FIGURE 13: Measured load and deflection curves of slab specimens.

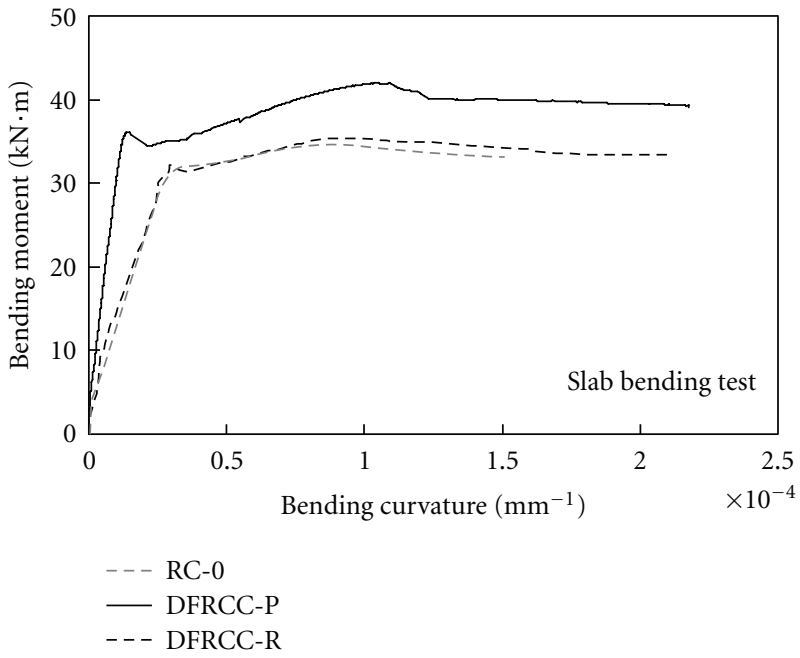

FiguRE 14: Measured bending moment and curvature curves of slab specimens.

which are the maximum deflection to yield deflection ratio, of Specimens RC-0, DFRCC-P, and DFRCC-R were 3.29, 5.15 , and 3.64, respectively. The values of measured moments and deformation responses of each slab specimen at first yielding of tensile reinforcement and maximum values are presented in Table 6.

\section{Conclusions}

This paper presents experimental studies not only on the manufacture of an extruded DFRCC panel, which exhibits multiple cracking and pseudo-deformation-hardening behavior, but also on an RC composite slab system developed by applying the extruded DFRCC panel. A series of experimental investigations were carried out to investigate the flexural behavior of both the extruded DFRCC panel and the RC composite slab system with the extruded DFRCC panel. 
TABLE 6: Experimental results of slab specimens.

\begin{tabular}{lcccccccc}
\hline Specimen name & $\begin{array}{c}\text { Yield } \\
\text { moment } \\
(\mathrm{kN} \cdot \mathrm{m})\end{array}$ & $\begin{array}{c}\text { Yield } \\
\text { deflection } \\
(\mathrm{mm})\end{array}$ & $\begin{array}{c}\text { Yield } \\
\text { curvature } \\
\left(10^{-5} / \mathrm{mm}\right)\end{array}$ & $\begin{array}{c}\text { Max. } \\
\text { moment } \\
(\mathrm{kN} \cdot \mathrm{m})\end{array}$ & $\begin{array}{c}\text { Max. deflection } \\
(\mathrm{mm})\end{array}$ & $\begin{array}{c}\text { Max. } \\
\text { curvature } \\
\left(10^{-4} / \mathrm{mm}\right)\end{array}$ & $\begin{array}{c}\text { Deflection } \\
\text { ductility } \\
\text { ratio }\end{array}$ & $\begin{array}{c}\text { Curvature } \\
\text { ductility } \\
\text { ratio }\end{array}$ \\
\hline RC-0 & 31.6 & 28.4 & 3.09 & 34.6 & 93.5 & 1.53 & 3.29 & 4.95 \\
DFRCC-P & 35.8 & 21.4 & 1.63 & 41.8 & 110 & 2.18 & 5.15 & 13.4 \\
DFRCC-R & 32.1 & 28.0 & 2.96 & 36.2 & 102 & 2.11 & 3.64 \\
\hline
\end{tabular}

From the panel bending test, it was found that deformationhardening DFRCC can be obtained with dry mixing of materials and PVA fiber, wet mixing, extrusion, and high-temperature curing. The deflection ductility and flexural strength of the extruded DFRCC developed in this study were 9.01 and 37.0 $\mathrm{MPa}$, respectively. The maximum moment, maximum curvature, and curvature ductility of the composite slab proposed in this study increased $21 \%, 42 \%$, and $170 \%$, respectively, compared with those values of a conventional $\mathrm{RC}$ slab. From the bending test results of the composite slab, it was verified that the stiffness, load-bearing capacity, and ductility of slab can be improved by applying the extruded DFRCC panel to the slab system. Furthermore, it was also verified that the crack width of a slab can be controlled by applying the extruded DFRCC panel.

\section{Acknowledgments}

This research was supported by a Grant (11CHUD-C0582051) from High-Tech Urban Development Program funded by the Ministry of Land, Transport and Maritime Affairs of the Korean Government. This research was also supported by Basic Science Research Program through the National Research Foundation of Korea (NRF) funded by the Ministry of Education, Science and Technology (no. 2011-0020027).

\section{References}

[1] V. C. Li, "From micromechanics to structural engineeringthe design of cementitious composites for civil engineering applications," Journal of Structural Mechanics and Earthquake Engineering, vol. 10, no. 2, pp. 37-48, 1993.

[2] Y. Y. Kim, G. Fischer, and V. C. Li, "Performance of bridge deck link slabs designed with ductile engineered cementitious composite (ECC)," ACI Structural Journal, vol. 101, no. 6, pp. 792$801,2004$.

[3] C. G. Cho, G. J. Ha, and Y. Y. Kim, "Nonlinear model of reinforced concrete frames retrofitted by in-filled HPFRCC walls," Structural Engineering and Mechanics, vol. 30, no. 2, pp. 211-223, 2008.

[4] C. K. Y. Leung, "Design criteria for pseudoductile fiberreinforced composites," Journal of Engineering Mechanics, vol. 122, no. 1, pp. 10-18, 1996.

[5] D. B. Marshall and B. N. Cox, "A J-integral method for calculating steady-state matrix cracking stresses in composites," Mechanics of Materials, vol. 7, no. 2, pp. 127-133, 1988.

[6] V. C. Li and C. K. Y. Leung, "Steady-state and multiple cracking of short random fiber composites," Journal of Engineering Mechanics, vol. 118, no. 11, pp. 2246-2264, 1992.
[7] M. D. Lepech and V. C. Li, "Large-scale processing of engineered cementitious composites," ACI Materials Journal, vol. 105, no. 4, pp. 358-366, 2008.

[8] Y. Y. Kim, G. Fischer, Y. M. Lim, and V. C. Li, "Mechanical performance of sprayed engineered cementitious composite using wet-mix shotcreting process for repair applications," ACI Materials Journal, vol. 101, no. 1, pp. 42-49, 2004.

[9] Y. Shao, S. Marikunte, and S. P. Shah, "Extruded fiberreinforced composites," Concrete International, vol. 17, no. 4, pp. 48-52, 1995.

[10] Y. Shao and S. P. Shah, "Mechanical properties of PVA fiber reinforced cement composites fabricated by extrusion processing," ACI Materials Journal, vol. 94, no. 6, pp. 555-564, 1997.

[11] H. Stang and V. C. Li, "Extrusion of ECC-material," in Proceedings of the High Performance Fiber Reinforced Cement Composites 3 (HPFRCC3 '99), H. W. Reinhardt and A. Naaman, Eds., pp. 203-212, Chapman \& Hall, 1999.

[12] Y. Akkaya, A. Peled, and S. P. Shah, "Parameters related to fiber length and processing in cementitious composites," Materials and Structures, vol. 33, no. 232, pp. 515-524, 2000.

[13] H. Takashima, K. Miyagai, T. Hashida, and V. C. Li, "A design approach for the mechanical properties of polypropylene discontinuous fiber reinforced cementitious composites by extrusion molding," Engineering Fracture Mechanics, vol. 70, no. 7-8, pp. 853-870, 2003.

[14] K. Rokugo, T. Kanda, H. Yokota, and N. Sakata, "Outline of JSCE recommendation for design and construction of multiple fine cracking type fiber reinforced cementitious composite," in Proceedings of the 5th International RILEM Workshop on High Performance Fiber Reinforced Cement Composites(HPFRCC5 '07), Reinhardt and Naaman, Eds., pp. 2032012, 2007. 

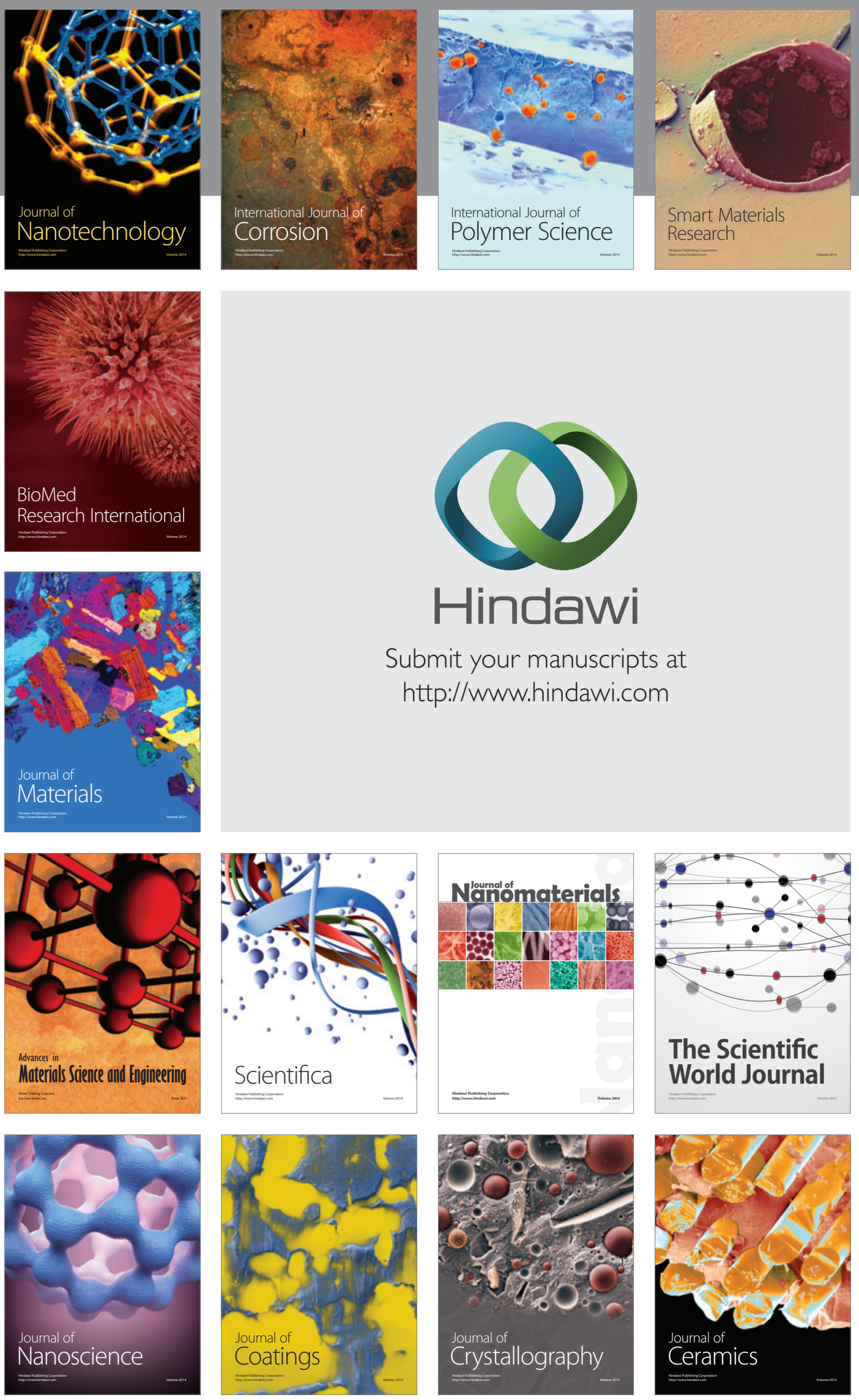

The Scientific World Journal

Submit your manuscripts at

http://www.hindawi.com

\section{World Journal}

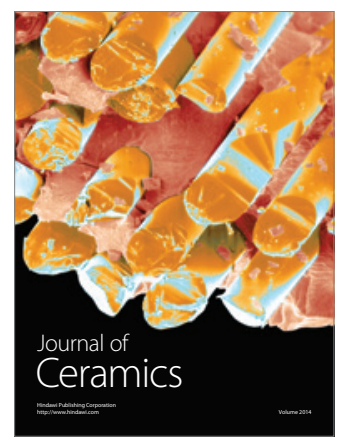

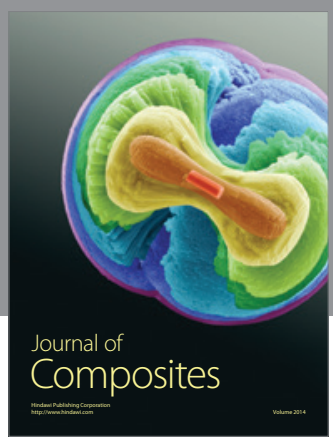
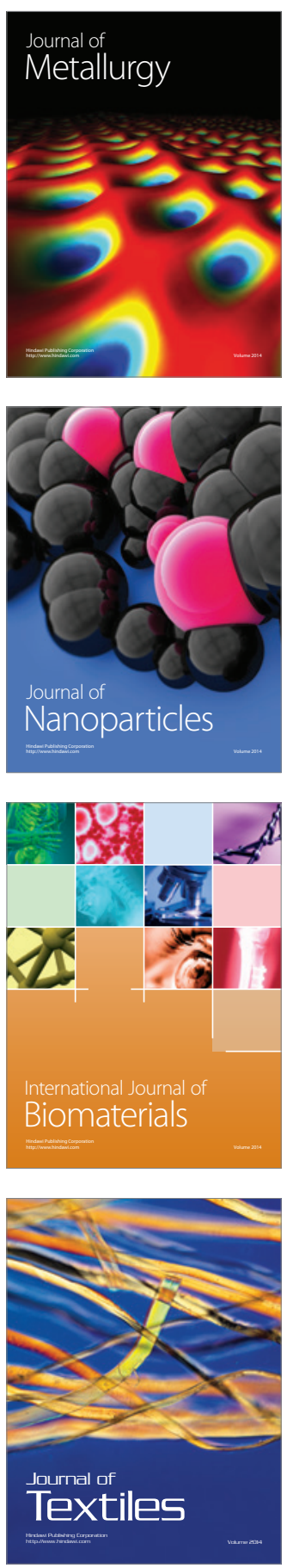